\title{
Can tablets be used as a simulator for automated external defibrillation during cardiopulmonary resuscitation courses?
}

\author{
IVOR KOVIC ${ }^{1}$ DINKA LULIC ${ }^{2}$, FRANKO HALLER ${ }^{3}$, JOSIP DRUZIJANIC ${ }^{4}$, ILEANA LULIC \\ ${ }^{1}$ Istria County Institute of Emergency Medicine, Emergency Medical Service Pazin, Pazin, Croatia \\ ${ }^{2}$ University Hospital "Sisters of Mercy", Zagreb, Croatia \\ ${ }^{3}$ Zagreb County Health Center, Health Center Samobor, Samobor, Croatia \\ ${ }^{4}$ First Aid Student Team Project, Croatian Medical Students' International Committee, Zagreb, Croatia \\ ${ }^{5}$ Primorsko-goranska County Institute of Emergency Medicine, Emergency Medical Service Rijeka, Rijeka, Croatia
}

Corresponding author:

Ivor Kovic

Istria County Institute of Emergency Medicine

Emergency Medical Service Pazin

Jurja Dobrile 1.52 000 Pazin. Croatia

Phone: $+385-91-1234598$

E-mail:ivorkovic@gmail.com

\section{ABSTRACT}

Background. A novel, tablet-based automated external defibrillator (AED) simulator has been developed to facilitate AED training.

Objective. To evaluate if the tablet AED simulator (an AED simulator based on mobile technology (M-AED)) can be successfully used during cardiopulmonary resuscitation (CPR) courses. To test medical and dental students' CPR attitudes, knowledge and skills, and evaluate the impact of a one day CPR course.

Methods. One hundred and twenty-four medical and dental students of University of Zagreb participated in a basic life support and automated external defibrillator (BLS/AED) course. All students filled out demographic, CPR attitudes and knowledge questionnaires before and after the course. Half of the students practised AED skills during the course on a conventional AED trainer (C-AED), and half on MAED. All underwent assessment of CPR skills after the course with C-AED. Those that used M-AED during training, rated its use.

Results. All students successfully completed the assessment of skills after the course, with no significant difference in the number of those who had to be retested between C-AED and M-AED. A significant improvement in CPR attitudes and knowledge was noted after the course among all students, with no difference between CAED and M-AED groups. M-AED as an AED trainer was highly rated.

Conclusions. Tablet based AED simulators can be effectively utilized during BLS/ AED courses as a substitute for conventional AED trainers.

Key words: defibrillators, computer simulation, mobile applications, cardiopulmonary resuscitation, European Resuscitation Council Guidelines

\section{INTRODUCTION}

Early defibrillation has the potential to save lives of many sudden cardiac arrest (SCA) victims. (1) Chances of survival are highest if bystanders act immediately after collapse and attempt defibrillation in the electrical or circulatory phase of SCA. $(2,3)$ Public access defibrillation (PAD) programmes have been established to empower bystanders to deliver early defibrillation, but have so far produced ambivalent results. (3-5) Although the evidence to support the benefits of public access automated external defibrillators (AEDs) is strong, $(3,5-7)$ unfortunately these lifesaving devices are often used only in a minority of SCA cases, even in areas where they are readily available. $(4,7)$ Education of the public is one of the crucial factors to increase awareness, willingness and knowledge to use AEDs. (8) Mobile technology has been shown to posses a great lifesaving potential for strengthening the Chain of Survival, and can also be used for AED education. (9)

\section{MOBILE AED TRAINING SOLUTION}

During basic life support and automated external defibrillation (BLS/AED) courses, participants are typically introduced to AEDs in the form of a trainer device. AED trainers are devices that simulate actual AEDs in appearance, operation, and voice prompts. They are commonly produced by AED manufacturers to match different AED models on the market. 'Mobile AED training solution' (Ivor Medical, Rijeka, Croatia), based on mobile technology, is a cost saving and versatile alternative to traditional AED trainers. (10) It consists of three components: AED trainer application for $\mathrm{iPad}^{\circledast}$ tablet (Apple Inc., Cupertino, USA), AED remote application for iPhone $^{\circledast}$ smartphone (Apple Inc., Cupertino, USA), and custom AED training pads for tablets (figure 1). 'AED trainer application' runs on a tablet and replicates all the universal features of existing AEDs, including step-by-step instructions and the ability to physically push a button to deliver shock. 'AED remote application' runs on a smartphone, allowing wireless and real time 
control of the AED trainer on the tablet in order to change scenarios or simulate various conditions such as low battery or poor connection of pads. Finally, custom AED training pads, which can be applied to all standard cardiopulmonary resuscitation (CPR) manikins, incorporate a specific connector to attach to the tablet, producing a powerful training solution with all features of conventional AED trainers.

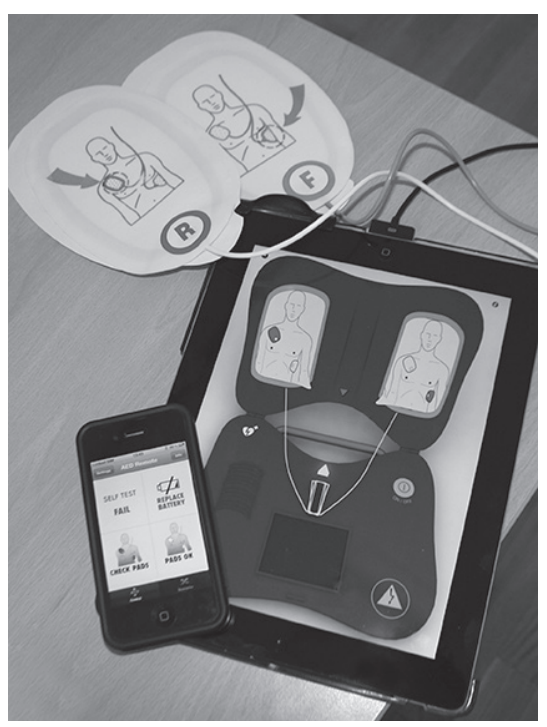

Figure 1. Mobile automatic external defibrillator (AED) training solution consisting of AED trainer application for $\mathrm{iPad}^{\otimes}$ tablet, AED remote application for $i$ Phone ${ }^{\oplus}$ smartphone, and custom AED training pads for tablet. (CIvor Medical

\section{GOALS}

Our primary goal was to investigate if the 'Mobile AED training solution' can be successfully used instead of conventional AED trainers during a BLS/AED course. Furthermore, we wanted to test BLS/AED attitudes, knowledge and skills of medical and dental students, and determine if a one-day BLS/AED course could significantly improve them.

\section{MATERIALS AND METHODS}

\section{Subjects}

From May 2012 to May 2013 a First Aid Student Team (FAST) of Croatian Medical Students' International Committee conducted 5 free BLS/AED courses with a total of 124 participants. (11) Participants were recruited among medical and dental students of the University of Zagreb School of Medicine by announcements on the FAST website, (11) FAST Facebook page (Facebook Inc., Menlo Park, USA), (12) and on bulletin boards in the school. Twenty-five places were offered for each course and were filled by those students who submitted an online registration form first, regardless of their study subject or year. Participants were not required to prepare for the course, and did not receive any materials from the organizers prior to its start.

\section{Courses}

BLS/AED courses were delivered according to the European Resuscitation Council (ERC) Guidelines for Resuscitation 2010. (1) They consisted of 4 lectures based on ERC materials (Adult BLS, recovery position, AED, and child BLS), which were followed by demonstrations and skill practice sessions. Courses were delivered over 8 hours during one day, including one and a half hours of lectures and three and a half hours of practice. During skill practice sessions, the student to instructor ratio was $3: 1$. Volunteer instructors were a combination of medical doctors and final year medical students with previous experience in teaching first aid courses. Furthermore, the medical director and principal instructors were all certified ERC instructors.

\section{Materials}

Dedicated faculty, lecturing and training rooms were setup at the course venue.

Standard Laerdal Little Anne ${ }^{\circledast}$ AED Training manikins (Laerdal Medical, Stavanger, Norway) were used during demonstrations, practice and testing of skills. Laerdal HeartStart FRx Trainer (Laerdal Medical, Stavanger, Norway) was used as a conventional AED trainer (C-AED) and 'Mobile AED training solution' (Ivor Medical, Rijeka, Croatia) was used as an AED simulator based on mobile technology (M-AED).

A simple demographic questionnaire was utilized before the course to gather participants' demographic data and previous CPR experience. Participants' BLS/AED knowledge was evaluated using a written test with 20 single best answer questions. The same written test, with a randomised order of questions, was filled out before and after the course and it included questions about adult CPR $(\mathrm{N}=10)$, the recovery position $(\mathrm{N}=2)$, AED $(\mathrm{N}=6)$, and child CPR $(\mathrm{N}=2)$.
Participants' attitudes towards CPR were assessed before and after the course using 4 statements with answers offered on a Likert type scale, where " 1 " indicated strongly disagree, " 2 " disagree, " 3 " undecided, " 4 " agree, and " 5 " strongly agree with a particular statement. Additionally, participants who used the 'Mobile AED training solution' during AED training sessions, rated its utility after the course using 4 statements with Likert type scale answers. During assessment of BLS/AED skills after the course, instructors used BLS/AED assessment records by ERC. All of the instruments were tested during a pilot study. (13)

\section{Study protocol}

Before the start of each course, the study's purpose and procedures were explained to all subjects, who signed a written consent form before being included. Students were then randomly assigned to one of 4 practice groups and filled out the demographic questionnaire, written $\mathrm{CPR}$ knowledge test and CPR attitudes questionnaire. All the data were gathered anonymously, with students choosing their own unique code, which they recorded on each sheet alongside their group number, to allow linking of pre- and post-course questionnaires. The course started with a lecture on adult BLS followed by faculty demonstrations of BLS skills and skill practice sessions in groups. The same pattern was employed for the recovery position, AED and child CPR lectures. During AED practice, half of the group used C-AED and the other half M-AED. After the course, students were tested again. Their CPR knowledge and attitudes were tested by the same questionnaires they filled out before the course, with an additional questionnaire for those students who used M-AED during practice sessions to rate its usefulness. Furthermore, students individually attended assessment of their BLS/AED skills by two instructors, who independently rated their performance using written assessment records. During skills testing, each student was presented with the same adult CPR scenario, and provided with a C-AED when they asked for an AED. If they failed to perform crucial lifesaving procedures or carried out potentially harmful actions, students had another opportunity to pass the assessment during the same day with another pair of instructors.

\section{Statistical analysis}

The results are shown with a mean and 
standard deviation (SD). Student's t-test and chi-squared test were used to test the differences between groups that used CAED and M-AED based on age, gender, previous CPR courses, previous real life $\mathrm{CPR}$, and retesting during assessment of CPR skills. Based on a satisfactory coefficient of internal consistency, it was decided to form a single measure of CPR attitudes $(\alpha=0.74)$, and attitudes toward M-AED $(\alpha=0.86)$. Four answers regarding CPR and M-AED attitudes were summarized and the total score for each subject was computed. The total score range was 4 to 20 for both CPR and M-AED attitudes. Two-way analysis of variance was used to compare average CPR attitudes total scores and knowledge test scores between groups that used C-AED and M-AED, as well as between before and after course measurements. Effects of independent variables were additionally decomposed using paired and unpaired t-tests. The Bonferroni method was used to correct for multiple comparisons. The two-tailed level of significance was set at 0.05 , and all statistical analyses were performed using SPSS for Windows, Version 15.0 (SPSS Inc., Chicago, USA).

\section{RESULTS}

Out of the 125 students that applied, 124 attended a BLS/AED course and signed a written consent. Their baseline characteristics, as well as previous CPR experience are presented in table 1.

Table 1. Characteristics and cardiopulmonary resuscitation $(C P R)$ experience of study participants.

\begin{tabular}{ll}
\hline Age & $\frac{22.81 .98^{* *}}{19-29^{* * *}}$ \\
\hline
\end{tabular}

\section{Gender}

\begin{tabular}{ll}
\hline Female & $85(68.5)^{\star}$ \\
\hline Study subject & \\
\hline Medicine & $74(59.7)^{\star}$ \\
Dentistry & $50(40.3)^{\star}$
\end{tabular}

\section{Study year}

\begin{tabular}{ll}
\hline 1 & $4(3.1)^{*}$ \\
\hline 2 & $25(20.2)^{*}$ \\
\hline 3 & $25(20.2)^{*}$ \\
\hline 5 & $27(21.8)^{*}$ \\
\hline 6 & $33(26.6)^{*}$ \\
\hline
\end{tabular}

\begin{tabular}{|c|c|}
\hline \multicolumn{2}{|c|}{ Previous CPR course } \\
\hline Yes & $47(37.9)^{*}$ \\
\hline No & $77(62.1)^{\star}$ \\
\hline \multicolumn{2}{|c|}{ Performed real life CPR } \\
\hline Yes & $5(4.0)^{*}$ \\
\hline No & $119(96)^{*}$ \\
\hline \multicolumn{2}{|c|}{${ }^{\star} \mathrm{N}(\%)$} \\
\hline \multicolumn{2}{|c|}{${ }^{* *}$ Mean \pm SD } \\
\hline$* * * \mathrm{R}$ & \\
\hline
\end{tabular}

Out of those who had previous CPR education, $13(28 \%)$ received it at medical school, $12(25 \%)$ at driving school, and 4 (8\%) as Red Cross volunteers.

There were significant differences in CPR attitudes and knowledge before and after the course (table 2). No differences were observed between the groups that practised on C-AED and those that used MAED in CPR attitudes before $(2.3 \pm 0.84$ vs. $2.3 \pm 0.88, \mathrm{t}(122)=0.14, \mathrm{p}=0.9)$ and after the course $(4.7 \pm 0.32$ vs. $4.7 \pm 0.35$, $\mathrm{t}(122)=0.07, \mathrm{p}=0.9)$, or CPR knowledge before $(36.8 \pm 11.3$ vs. $39.7 \pm 12.2, \mathrm{t}(122)=$ $1.4, \mathrm{p}=0.17)$ and after the course (85.7 \pm 8.6 vs. $87.9 \pm 7.8, \mathrm{t}(122)=1.5, \mathrm{p}=0.13)$.

Table 2. Comparison of cardiopulmonary resuscitation (CPR) attitudes and knowledge test scores before and after a basic life support and automated external defibrillation (BLS/AED) course.

\begin{tabular}{lllll}
\hline & Before the course & After the course & Statistics & P \\
\hline & (Mean SD) & (Mean SD) & $\mathrm{F}$ & $<\mathbf{0 . 0 0 1}$ \\
\hline $\begin{array}{l}\text { Attitudes (total score) } \\
\begin{array}{l}\text { Knowledge (\% correct } \\
\text { answers) }\end{array}\end{array}$ & $\mathbf{9 . 1 3 . 4}$ & $\mathbf{1 8 . 9} \mathbf{1 . 3}$ & $\mathbf{1 0 5 3}^{*}$ & $<0.001$ \\
\hline All & 38.311 .8 & & & $<0.001$ \\
\hline Adult CPR & 32.717 .4 & 86.88 .2 & $1825.4^{*}$ & 0.007 \\
\hline Recovery position & 73.830 .2 & 90.210 .4 & $1007.4^{*}$ & $<0.001$ \\
\hline AED & 37.018 .9 & 82.724 .7 & $7.6^{*}$ & $<0.001$
\end{tabular}

* $\mathrm{df}=122$

All students successfully completed the assessment of skills. In total $22(17.7 \%)$ students failed their first assessment, but successfully passed during the repeated skills' test. There was no significant differ- ence in the number of students failing their initial assessment between those that used $\mathrm{C}-\mathrm{AED}$ or M-AED during training (9 vs. $\left.13, \chi^{2}=0.1, p=0.7\right)$.
M-AED as an AED simulator was highly rated among students that used it during training (mean total score $=17.9 \pm 3.0)($ table 3). 
Table 3. Attitudes towards tablet based automated external defibrillator (AED) simulator

\begin{tabular}{|c|c|}
\hline Statements & Mean SD \\
\hline I think that the use of a tablet during AED practice did not diminish my educational experience & 4.50 .9 \\
\hline Tablet AED simulator is a useful tool to practice AED skills & 4.70 .5 \\
\hline I did not have any additional difficulties during assessment of skills, because I trained on a tablet AED simulator & 4.50 .9 \\
\hline I did not notice any major differences in operation between the tablet AED simulator and conventional AED trainer & 4.31 \\
\hline
\end{tabular}

\section{DISCUSSION}

Our study has shown that the tested medical and dental students of University of Zagreb School of Medicine, regardless of their study year, have poor BLS/AED knowledge. This lack of knowledge had a strong impact on students' attitudes towards CPR, which they demonstrated with great doubts expressed regarding the ability to perform basic first aid. Such effect has been previously demonstrated in other medical schools lacking formal CPR education. (14) On the positive side, we have demonstrated that a single one-day BLS/ AED course can have dramatic effects on immediate CPR knowledge, skills and attitudes among medical and dental students, which was also shown by Sopka and others. (15) Student projects, like FAST, (11) which offer free CPR courses, are an excellent example of students taking initiative and organizing themselves to address the shortcomings of their school curriculum. However, in order to consistently deliver standardized CPR education to all the students, and turn them into not only excellent CPR providers, but also CPR leaders and promoters, $(16,17)$ requires mandatory and repetitive CPR education in medical school. $(18,19)$

One of the obstacles for wider implementation of BLS/AED courses and familiarization with AEDs in general, especially in developing countries, are financial costs including acquisition of necessary training equipment. Conventional AED trainers, which are typically utilized during education, currently cost anywhere between 186 and 480 pounds sterling. (20) This represents a substantial investment for a device that serves only one purpose, to usually mimic just one specific model of a real life AED. Tablets, mobile computers with touchscreen, are one of the most rapidly adopted technologies in history and are owned by $42 \%$ of American adults according to a survey from the start of 2014. (21) Furthermore, with ever declining prices and addition of new features, tab- lets are increasingly becoming integrated into the teaching process in schools. Their advanced capabilities allow them to easily mimic all aspects of AEDs, except the exact physical form, including visual and voice prompts and the ability to push a button to deliver shock. Furthermore, applications for tablets can be developed to mimic all the possible variations of AEDs available on the market with all of their specificities. In our study we decided to put to test one such AED training solution based on mobile technology with a universal AED simulator running on a tablet aimed to emulate all the ubiquitous features of AEDs designed according to the latest CPR guidelines. (10) The tested tablet AED simulator can be used on its own to familiarize the user with the operation of a typical AED, but also in conjunction with a smartphone application and custom training pads during a BLS/AED course. Smartphone application acts as a remote control that allows the instructor to wirelessly and in real time control the AED simulator on the tablet. This provides the instructor with numerous possibilities of enhancing the training experience while changing between shock and no-shock scenarios, as well as simulating malfunction of device, empty battery or incorrect position of pads. Adding custom AED pads that connect to the tablet makes the 'Mobile AED training solution' physically similar to a conventional AED and usable with standard CPR manikins. During BLS/AED courses, our study participants responded extremely well to the 'Mobile AED training solution' and in fact based on experiences of the instructors, many of the students did not even realize they were practising on a tablet and not on a real AED. This group of students did not practise on or had any contact with a conventional AED trainer before the assessment of skills. Nevertheless, they performed equally well with no difference in the number of those failing the initial skills' assessment compared to their colleagues who used the same conventional AED trainer during practise and testing. Furthermore, when asked to assess the tablet AED simulator after the course, students highly rated its use and agreed that it is a useful education tool that did not negatively influence their ability to use a conventional AED trainer.

\section{LIMITATIONS AND FUTURE STUDIES}

During delivery of BLS/AED courses, we educated and tested only a fraction of medical and dental students from University of Zagreb School of Medicine. Additionally, we included only those students who volunteered to participate in the course, who potentially had less CPR knowledge than the ones who did not apply. Because of these reasons we cannot draw conclusions about CPR knowledge and attitudes of all the students in the school.

Before and after BLS/AED courses, we tested students' CPR knowledge and attitudes, but due to time constraints we only tested their skills after the course. However due to poor CPR knowledge and attitudes, as well as experiences of instructors during practice sessions, we can assume their prior CPR skills were equally poor, but cannot provide direct measures of improvement.

We tested the 'Mobile AED training solution' based on tablets on young and technology knowledgeable students, but cannot be certain that other groups of users would react to this educational tool in the same positive manner. Future studies should evaluate tablet AED simulators on other groups of people, especially the layman and the elderly. Furthermore these studies should test if tablet AED simulators alone, without pads, manikins and CPR courses, can raise AED awareness and knowledge, as well as the willingness to use them in a real emergency.

\section{CONCLUSIONS}

In the era of increased efforts to educate the public about the use of AEDs and various worldwide initiatives to implement 
BLS/AED training as early as elementary school, there are still students finishing medical school without basic CPR knowledge and skills. Medical schools should make CPR an essential part of their curriculum to empower students in their future roles as clinicians and CPR advocates. AED simulators on tablets can be successfully used during BLS/AED training, as a versatile and cost saving alternative to conventional AED trainers. With rapid dissemination and great availability of tablets,
AED simulator applications have a strong potential to reach and educate vast numbers of people, leading to wider adoption and use of AEDs and ultimately better survival of SCA.

\section{ACKNOWLEDGEMENT}

We would like to thank the University of Zagreb, School of Medicine for providing the venue for BLS/AED courses. We are extremely grateful for the time and efforts of our volunteer instructors, supporting staff from First Aid Student Team of Croatian Medical Students' International Committee and participants. Finally we wish to thank Stiv Trade from Zagreb, official distributor of Laerdal Medical in Croatia, for providing us with CPR manikins and conventional AED trainers.

\section{REFERENCES}

1. Koster RW, Baubin MA, Bossaert LL, Caballero A, Cassan P, Castrén M, et al. European Resuscitation Council Guidelines for Resuscitation 2010 Section 2. Adult basic life support and use of automated external defibrillators. Resuscitation 2010;81:1277-92.

2. Weisfeldt ML, Becker LB. Resuscitation after cardiac arrest: a 3-phase time- sensitive model. JAMA 2002;288:3035-8.

3. Murakami Y, Iwami T, Kitamura T, Nishiyama C, Nishiuchi T, Hayashi Y, Kawamura T; Utstein Osaka Project. Outcomes of out-ofhospital cardiac arrest by public location in the public-access defibrillation era. J Am Heart Assoc 2014;3:e000533.

4. Deakin CD1, Shewry E, Gray HH. Public access defibrillation remains out of reach for most victims of out-of-hospital sudden cardiac arrest. Heart 2014;100:619-23.

5. Nielsen AM1, Folke F, Lippert FK, Rasmussen LS. Use and benefits of public access defibrillation in a nation-wide network. Resuscitation 2013;84:430-4.

6. Eckstein M. The Los Angeles public access defibrillator (PAD) program: ten years after. Resuscitation 2012;83:1411-2.

7. Weisfeldt ML, Sitlani CM, Ornato JP, Rea T, Aufderheide TP, Davis D, et al; ROC Investigators. Survival after application of automatic external defibrillators before arrival of the emergency medical system: evaluation in the resuscitation outcomes consortium population of 21 million. J Am Coll Cardiol 2010;55:1713-20.

8. Schober P, van Dehn FB, Bierens JJ, Loer SA, Schwarte LA. Public access defibrillation: time to access the public. Ann Emerg Med 2011;58:240-7.

9. Kovic I, Lulic I. Mobile phone in the chain of survival. Resuscitation 2011;82:776-9.

10. AED Training Apps [Internet]. Rijeka: Ivor Medical; [cited 2014 July 24]. Available from: http://ivormedical.com/products/aedtrainer-app/.

11. First Aid Student Team [Internet]. Zagreb: Croatian Medical Students' International Committee; [cited 2014 July 24]. Available from: http://cromsic.hr/studentska-ekipa-prve-pomoci/.

12. Facebook: First Aid Student Team [Internet]. Zagreb: Croatian Medical Students' International Committee; [cited 2014 July 24$].$ Available from: https://www.facebook.com/stepp.fast/.

13. Kovic I, Lulic D, Haller F, Druzijanic J, Lulic I. Can the iPad be used as an automated external defibrillator (AED) trainer during basic life support and automated external defibrillator (BLS/AED) courses? A preliminary study. Resuscitation October 15 2012;83:e114.

14. Freund Y, Duchateau FX, Baker EC, Goulet H, Carreira S, Schmidt M, et al. Self-perception of knowledge and confidence in performing basic life support among medical students. Eur J Emerg Med 2013;20:193-6.

15. Sopka S, Biermann H, Druener S, Skorning M, Knops A, Fitzner C, et al. Practical skills training influences knowledge and attitude of dental students towards emergency medical care. Eur J Dent Educ 2012;16:179-86.

16. Toner P, Connolly M, Laverty L, McGrath P, Connolly D, McCluskey DR. Teaching basic life support to school children using medical students and teachers in a 'peer-training' model-results of the 'ABC for life' programme. Resuscitation 2007;75:169-75.

17. Robak O, Kulnig J, Sterz F, Uray T, Haugk M, Kliegel A, et al. CPR in medical schools: learning by teaching BLS to sudden cardiac death survivors-a promising strategy for medical students? BMC Med Educ 2006;6:27.

18. Nicol P, Carr S, Cleary G, Celenza A. Retention into internship of resuscitation skills learned in a medical student resuscitation program incorporating an Immediate Life Support course. Resuscitation 2011;82:45-50.

19. Lešnik D, Lešnik B, Golub J, Križmarić M, Mally S, Grmec S. Impact of additional module training on the level of basic life support knowledge of first year students at the University of Maribor. Int J Emerg Med 2011;4:16.

20. Defibshop: AED Training Units [Internet]. Manchester: Imperative Training Ltd; [cited 2014 July 24]. Available from: http://www. defibshop.co.uk/aed-training-units.

21.Zickuhr K, Lee R. E-reading Rises as Device Ownership Jumps [Internet]. Washington, DC: Pew Internet \& American Life Project; [cited 2014 July 24]. Available from: http://www.pewinternet.org/2014/01/16/e-reading-rises-as-device-ownership-jumps/ 